\section{RICYDE. Revista Internacional de Ciencias del Deporte} doi: $10.5232 /$ ricyde

Rev. int. cienc. deporte

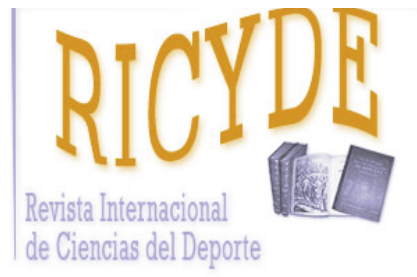

RICYDE. Revista Internacional de Ciencias del Deporte VOLUMEN XIV - AÑO XIV

Paginas:280-296 ISSN:1885-3137 Número: 53 - julio - 2018

\title{
Las etapas del asociacionismo deportivo en Chile y su relación con el contexto histórico (finales siglo XIX-2012) \\ Stages of sports associationism in Chile and it's relationship with the historical context (late nineteenth-2012)
}

\author{
Carlos Matus $^{1}$, Anna Vilanova ${ }^{2}$, Núria Puig ${ }^{2}$ y Jorge Vidal ${ }^{3}$
}

1. Facultad de Educación, Departamento de Ciencias del Deporte y Acondicionamiento Físico, Universidad Católica de la Santísima Concepción, Chile. Grup d'Investigació Social i Educativa de l'Activitat Física i l'Esport (GISEAFE), Institut Nacional d'Educació Física de Catalunya (INEFC), Universitat de Barcelona (UB), España.

2. Grup d'Investigació Social i Educativa de l'Activitat Física i l'Esport (GISEAFE), Institut Nacional d'Educació Física de Catalunya (INEFC), Universitat de Barcelona (UB), España.

3. Escuela de Sociología, Universidad Academia de Humanismo Cristiano. Grupo de Estudios en Historia del Deporte, Chile.

\section{Resumen}

El siguiente artículo tiene como objetivo describir las etapas del asociacionismo deportivo de Chile en el contexto del desarrollo histórico de este país El método utilizado fue un cuestionario estandarizado cara a cara. Posteriormente, se realizó un trabajo estadístico basado en la distribución de la frecuencia, considerando como variable el año de fundación de dichas organizaciones. Los resultados se contrastaron mediante un análisis documental a períodos históricos y sociales de Chile, profundizando especialmente en las características del desarrollo de la sociedad civil. La muestra se compuso de 150 clubes. Los resultados muestran seis etapas: Hasta el año 1924, La influencia inglesa y los primeros clubes; desde 1925 a 1938, Surgimiento de otras organizaciones y diversificación; desde 1939 a 1973, Crecimiento del número de clubes; desde 1974 a 1990 , Limitaciones y control; desde 1991 al 2000, Reconstrucción de la sociedad civil; y desde 2001 al 2012, La consolidación. Estas etapas se relacionan con al contexto y a las condiciones económicas, políticas y sociales de la sociedad chilena.

Palabras clave: club deportivo; asociacionismo; historia; sociedad; organización deportiva; Chile

\section{Abstract}

The following article has as main objective to describe the stages of sports associationism in Chile within the context of historical development of the country. In order to collect data, face to face standard questionnaire was used, later a statistic research was done based on frequency distribution considering as variable the year of foundation of those sports organizations. Results were contrasted through documental analysis of social and historical periods in Chile, going in depth in some development of characteristics about civil society. The sample was made up of 150 sports clubs, the results showed six stages: until 1924, The English influence and firsts clubs; from 1939 and 1973, Rising of numbers of clubs; from 1974 to 1990, Limitations and control; from 1991 to 2000, Restoration of civil society framework; and from 2001 to 2012, the Strengthening. These stages are related to it's context and the social, political and economic conditions of the Chilean society.

Key words: Sports club; associationism; history; society; sports organization; Chile 
Matus, C.; Vilanova, A.; Puig, N., \& Vidal, J. (2018). Las etapas del asociacionismo deportivo en Chile y su relación con el contexto histórico (finales siglo XIX-2012). RICYDE. Revista internacional de ciencias del deporte. 53(14), 280-296. https://doi.org/10.5232/ricyde2018.05308

\section{Introducción}

$\mathrm{U}^{\mathrm{n}}$ na forma de comprender el fenómeno deportivo moderno y su articulación social, asumiéndolo como un sistema abierto (Puig y Heinemann, 1991), es abordarlo desde el conocimiento de sus procesos de instauración y de desarrollo del asociacionismo, desde una perspectiva histórica, social y cultural (Pujadas y Santacana, 2003). En línea con lo anterior, Moreno (1993) indica que las entidades deportivas han estado relacionadas con la dinámica social de cada época. Ejemplo de ello, son los trabajos de Puig, Moreno y López (1996) y de Puig, García y López (1999a), en los que se reflexiona en torno a los procesos sociohistóricos de España y la relación que existe con las organizaciones deportivas de base voluntaria. Un resultado relevante y que ha servido como orientación para este artículo, es la propuesta desarrollada por Puig y col. (1996), donde se formula una tipología de las asociaciones deportivas españolas, en la cual se considera el período temporal en la que fue fundada la organización y algunas características como los deportes practicados, el número y la procedencia social y geográfica de los socios, entre otras variables. Otra evidencia es el estudio de los clubes deportivos catalanes también en España (Secretaria General de l'Esport, 2010), el cual propone una clasificación temporal de seis etapas históricas, concebidas principalmente por su influencia política y social en el sistema asociativo de Cataluña. Al observar esas fases, queda en evidencia que los diversos procesos por los que ha atravesado la sociedad catalana también han afectado al nacimiento y características de sus clubes deportivos. En este mismo contexto de las organizaciones deportivas, pero empleando otros enfoques, se encuentran por ejemplo los trabajos de Torrebadella (2012), quien relata particularmente la instalación del fútbol en dicho país, pero específicamente en la ciudad de Barcelona, a fines del siglo XIX. Destaca en esta investigación la influencia que tuvieron los inmigrantes ingleses en este proceso, y como a través de la práctica del fútbol en esta ciudad, el tejido asociativo fue germinando y creciendo hacia el resto del país. Así mismo, y bajo un enfoque histórico-lingüístico, Torrebadella y Nomdedeu (2013) explican cómo se gestó e instaló el término "futbol" y "balompié" en la lengua castellana, provenientes del anglicismo "foot-ball".

En este mismo sentido, Simón (2015) manifiesta desde una perspectiva general de España qué si bien Barcelona fue el principal centro del desarrollo deportivo en ese país, desde las últimas décadas del siglo XIX y hasta el inicio de la guerra civil, otras ciudades como Bilbao, Madrid y San Sebastián, también presenciaron la implantación del deporte inglés y las primeras asociaciones deportivas compuestas principalmente por inmigrantes ingleses y de otros países de Europa que llegaban a dichas ciudades a ofrecer sus conocimientos técnicos. Otro medio por el cual ingresó el deporte moderno en España se ubica en los jóvenes que pertenecían a familias burguesas que por estudios o prácticas iban al extranjero, pero que a su regreso comenzaban a fomentar deportes que escapaban a las tradicionales prácticas aristocráticas, como la caza o la hípica, fomentando en cambio el fútbol, el atletismo, el boxeo, entre otros. A la par de este crecimiento de practicantes y deportes, se comenzaron también a gestar los primeros clubes deportivos, los cuales dieron paso a la creación de asociaciones y federaciones. Estas apreciaciones coinciden con lo señalado por Lagardera y Puig (1996) y Puig, García y López (1999b), respecto a la influencia del deporte inglés en la gestación del asociacionismo español y particularmente del desarrollado en Cataluña. 
Matus, C.; Vilanova, A.; Puig, N., \& Vidal, J. (2018). Las etapas del asociacionismo deportivo en Chile y su relación con el contexto histórico (finales siglo XIX-2012). RICYDE. Revista internacional de ciencias del deporte. 53(14), 280-296. https://doi.org/10.5232/ricyde2018.05308

Otros trabajos realizados en países europeos, confirman la misma situación, como en Gran Bretaña, dónde Kay (2013) realiza un análisis histórico sobre los clubes deportivos de tenis, golf y bowling durante el siglo XX. En este trabajo se focaliza la atención en las formas de adaptación a los cambios económicos y sociales, basándose en ámbitos como la pertenencia, la financiación y los aspectos sociales. En Finlandia, Koski (2012) determina una serie de cambios que se generaron en los clubes de ese país desde el año 1986 hasta el año 2006, siendo múltiples las variables que afectarían a estas organizaciones de acuerdo al momento histórico analizado. Entre los factores hallados se mencionan el envejecimiento de la población, la necesidad de contar con voluntarios y el mayor nivel educacional de las personas, entre otros. Esta investigación deja en evidencia que los clubes se ajustan o acomodan a las circunstancias que presenta la sociedad. Un análisis histórico y que presenta una asociación directa con este artículo, es el trabajo historiográfico realizado por Krüger (2013) con los clubes deportivos alemanes. En esta investigación, el autor analiza desde el siglo XIX en adelante la evolución de los clubes de dicho país, mediante el establecimiento de una serie de etapas históricas, las cuáles influenciaron el desarrollo y las características de estas organizaciones.

En Latinoamérica destacan los trabajos de Frydenberg, Daskal y Torres (2013), quienes estudian particularmente a los clubes de fútbol argentinos desde su fundación como organizaciones de prácticas sociales, caracterizadas por su flexibilidad y capacidad de adaptación a los diversos cambios que ha tenido dicha sociedad, concibiéndolas como instituciones que producen y reproducen la vida deportiva y comunitaria de los barrios. También se han publicado trabajos en Brasil, es el caso de Oviedo y Zarpellon (2012), quienes investigan la influencia de la segunda guerra mundial en la identidad de un club brasileño de remo, fundado por inmigrantes italianos, o de Fernandes da Silva y Zarpellon (2015) que estudian la instrumentalización del deporte a través del asociacionismo en Porto Alegre en el siglo XIX y mediados del siglo XX.

En el caso de Chile, los trabajos historiográficos del deporte nacional, y del asociacionismo en particular, aún se encuentran en una etapa incipiente o en espera de ser explotados. No obstante, existen algunos estudios que enfocan al deporte y al asociacionismo deportivo, desde una perspectiva social, política y barrial. Aquí por ejemplo surgen los trabajos de Guerrero (2005; 2006), Elsey (2012) y Miranda, Araneda, Jofré y González (2014), quienes estudian a los clubes deportivos sin fines de lucro, desde una dimensión localista, barrial y con el fin esencial de rescatar el patrimonio histórico de esas organizaciones. En una línea de continuidad con dichos estudios, en el trabajo de Ovalle y Vidal (2015), se encuentran investigaciones centradas en el nivel asociativo de los clubes deportivos chilenos, tanto en las organizaciones de obreros, como de los empleados públicos y en jugadores que organizaron el Sindicato de Futbolistas en la década del sesenta del siglo pasado. Los anteriores trabajos colaboran en el reconocimiento que se les ha otorgado a estas organizaciones en las diversas etapas de la historia reciente de Chile, entendidas como instituciones representativas de las diversas clases sociales. Por su parte, Elsey (2012), postula que los clubes deportivos de fútbol amateur constituyeron el espacio donde se construyó parte de la cultura política de los sectores populares durante una parte importante del siglo XX, cobrando gran relevancia, ya que estos sectores subalternos se encontraban excluidos de la participación en la institucionalidad política. Este espacio no sólo era de sociabilidad popular y ciudadanía, sino que también permitía observar las capacidades organizativas de los sectores populares, así como el tipo de redes que generaban para el desarrollo de la actividad deportiva. En una línea similar, Vidal (2014) otorga otra perspectiva, señalando que los clubes deportivos deben 
Matus, C.; Vilanova, A.; Puig, N., \& Vidal, J. (2018). Las etapas del asociacionismo deportivo en Chile y su relación con el contexto histórico (finales siglo XIX-2012). RICYDE. Revista internacional de ciencias del deporte. 53(14), 280-296. https://doi.org/10.5232/ricyde2018.05308

pensarse no sólo como entidades preocupadas de la recreación y el tiempo libre de sus asociados, sino como un espacio de construcción de ciudadanía y de desarrollo de capacidades organizativas de los sectores populares. Estas visiones sobre los clubes aún se encuentran en una fase incipiente y de desarrollo en Chile, no obstante, ya son un primer paso para comprenderlos mejor.

Si se entiende que estas instituciones son un espacio de construcción de la sociedad civil, resulta interesante analizarlos desde una perspectiva histórica y social que ayude a comprender con mayor profundidad como se ha gestado el desarrollo del asociacionismo deportivo en Chile. En este sentido, el objetivo del presente artículo es describir las etapas del asociacionismo deportivo de Chile en el contexto del desarrollo histórico de este país.

\section{Método}

\section{Participantes}

El estudio se realizó en el año 2013 en la región del Biobío en Chile, la cual tenía en aquel momento una población estimada de 2.086.833 habitantes (Instituto Nacional de Estadísticas, 2016). Se trata de la segunda región del país en número de habitantes, por detrás de la Región Metropolitana. Se divide administrativamente en cuatro provincias: Arauco, Biobío, Nuble y Concepción, las cuales contienen a 54 comunas en total.

En el estudio participaron 150 clubes privados, vigentes y sin fines de lucro de la región (fracción de muestreo de $45.6 \%$ de la población total). Ello implicó un margen de error del $5.9 \%$ y un nivel de confianza del $95.0 \%$. La muestra fue distribuida proporcionalmente para cada estrato (provincia), aplicando el criterio de afijación proporcional. En cuanto a la pregunta empleada para este artículo, ésta fue: ¿en qué año fue fundado su club?, a la cual otorgaron una respuesta válida, 142 clubes, los cuales estaban inscritos en el Registro Nacional de Organizaciones ${ }^{1}$ del Instituto Nacional de Deportes de Chile ${ }^{2}$.

\section{Procedimiento}

Este estudio forma parte de un proyecto de investigación de mayores dimensiones sobre la situación de los clubes deportivos chilenos, en el cual se aplicó un cuestionario estandarizado y multidimensional de forma presencial a los presidentes de los clubes o a algún otro miembro de la junta directiva. Este se basó para su diseño en uno empleado en Cataluña (Secretaria General de l'Esport, 2010), el cual a su vez se cimentó en uno realizado por Heinemann y Schubert (1994) en Alemania. Además, se consideró el cuestionario que utilizaron Cornejo, Salcedo y Matus (2009) en un estudio sobre clubes deportivos escolares chilenos. El cuestionario contó con una batería de 59 preguntas cerradas y una pregunta abierta. La media de duración de la cumplimentación fue de 57 minutos. La recogida de datos se realizó desde el uno de agosto hasta el treinta de noviembre del año 2013. Para este artículo solo se ha empleado la pregunta que abordaba el año de fundación del club

\footnotetext{
${ }^{1}$ En adelante RNO

2 En adelante IND. El organismo público y rector del deporte en Chile hasta el año 2013 fue el Instituto Nacional de Deportes (IND), entidad pública creada en el año 2001 a través de la Ley del Deporte nº 19712 (Ministerio del Interior) y a la cual se le concedió el rango de Subsecretaría dependiente del Ministerio Secretaría General de Gobierno. Esta figura mantuvo su jerarquía hasta la promulgación de la Ley "Crea el Ministerio del Deporte" n 20686 del año 2013 (Ministerio Secretaría General de Gobierno de Chile), que creó el Ministerio del Deporte (MINDEP), el cual pasó a ser el órgano superior de asesoramiento del Presidente(a) de la República en materias referidas a la actividad física y el deporte.
} 
Matus, C.; Vilanova, A.; Puig, N., \& Vidal, J. (2018). Las etapas del asociacionismo deportivo en Chile y su relación con el contexto histórico (finales siglo XIX-2012). RICYDE. Revista internacional de ciencias del deporte. 53(14), 280-296. https://doi.org/10.5232/ricyde2018.05308

deportivo. Cabe señalar que solo se consideraron clubes que habían sido fundados hasta el año 2012.

\section{Análisis de la información}

Para evidenciar los años de fundación de los clubes, se empleó la técnica de análisis de frecuencias. Respecto a los documentos que permitieron estructurar los períodos en los cuales surgen estas organizaciones, se utilizó la técnica de análisis documental de fuentes primarias y secundarias que abordaban la historia contemporánea de Chile, el desarrollo de la sociedad civil y el asociacionismo deportivo de ese país. El análisis permitió establecer un correlato entre el surgimiento de los clubes y la historia contemporánea del país. Ello ha derivado en la propuesta de diversas etapas del asociacionismo deportivo chileno.

\section{Resultados: la historia de Chile influye en la de sus clubes deportivos}

Lo que se presenta a continuación, corresponde a seis etapas que relacionan el contexto socio-histórico de Chile con el asociacionismo deportivo de ese país.

A continuación, la tabla 1 presenta la distribución de los clubes en relación al año de su fundación y la etapa a la cual se ha asociado. Posteriormente, se detalla y fundamenta cada período, estableciendo una relación con la frecuencia de clubes fundados.

Tabla 1. Las etapas en la fundación de los clubes deporticos chilenos $(\mathrm{n}=142)$

\begin{tabular}{|l|l|c|c|}
\hline \multicolumn{1}{|c|}{ Rango años } & \multicolumn{1}{|c|}{ Etapa } & $\begin{array}{c}\text { Clubes } \\
\text { constituidos } \\
f_{i}(\%)\end{array}$ & $\begin{array}{c}\text { Clubes } \\
\text { constituidos } \\
F_{i}(\%)\end{array}$ \\
\hline Hasta 1924 & Influencia inglesa y los primeros clubes & 3.5 & 3.5 \\
\hline $1925-1938$ & $\begin{array}{l}\text { Surgimiento de otras organizaciones y } \\
\text { diversificación }\end{array}$ & 0.7 & 4.2 \\
\hline $1939-1973$ & Crecimiento del número de clubes & 14.8 & 19.0 \\
\hline $1974-1990$ & Limitaciones y control & 2.8 & 21.8 \\
\hline $1991-2000$ & Reconstrucción de la sociedad civil & 10.6 & 32.4 \\
\hline $2001-2012$ & La consolidación & 67.6 & 100.0 \\
\hline$f_{i}=$ frecuencia absoluta \\
$F_{i}=$ frecuencia acumulada
\end{tabular}

\section{$1^{a}$ etapa. Hasta 1924. La influencia inglesa y los primeros clubes}

Hasta el año 1924 aproximadamente, se desarrolló en Chile un proceso de surgimiento y de instalación del deporte, tanto en su práctica individual (personal) como asociada (clubes). Las primeras disciplinas deportivas (a mediados del siglo XIX) tienen claramente una influencia inglesa (Santa Cruz, 2006), destacando entre ellas, el cricket, la cacería a caballo y la hípica. Esta emersión de deportes se materializa simultáneamente a la aparición de las primeras organizaciones deportivas, ya que en 1860 se crean en la ciudad portuaria de Valparaíso, el Valparaíso Cricket Club y el Valparaíso Hunt, los cuales en su esencia, eran clubes sociales en los que se practicaba deporte. El primer club eminentemente deportivo fundado en Chile y en Sudamérica- es el Valparaíso Paperchase Club, formado en el año 1870 (Modiano, 1997) y cuya especialidad fue la equitación. 
Matus, C.; Vilanova, A.; Puig, N., \& Vidal, J. (2018). Las etapas del asociacionismo deportivo en Chile y su relación con el contexto histórico (finales siglo XIX-2012). RICYDE. Revista internacional de ciencias del deporte. 53(14), 280-296. https://doi.org/10.5232/ricyde2018.05308

El proceso de incorporación del deporte moderno en Chile, fue muy similar al de algunos países europeos en cuanto a la influencia inglesa. Es el caso de España, Italia y Francia, donde, a través de sus puertos y ciudades industriales, se fue introduciendo el deporte mediante la llegada de británicos (ingleses, principalmente) que eran practicantes en sus países de origen y que llegaban a tierras extranjeras por motivos comerciales, industriales o diplomáticos (Pujadas y Santacana, 2003). En el caso de Chile, el deporte también entra por ciudades portuarias, como Valparaíso en el centro del país; Iquique y Antofagasta, en el norte; y Talcahuano (Concepción) en el sur. Estas localidades, en su calidad de puertos, recibían muchos barcos con extranjeros (británicos) que llegaban a Chile por motivos comerciales, principalmente. Como manifiesta Santa Cruz (2006), el deporte en Chile tuvo su origen en la aristocracia, ya que los británicos que incorporaron prácticas como el cricket, la caza, el golf y el tenis se relacionaban con las clases altas del país. Se desprende de ello que la proliferación del deporte también se gestó desde esos niveles hacia el resto de la sociedad.

Luego de algunos años y también por influencia inglesa, se comienza a practicar el fútbol, siendo el año 1889 cuando se disputa el primer partido formal (en la pista del Valparaíso Sporting Club), con la participación del Valparaíso F.C., el primer club de fútbol formalmente constituido en Chile. Prontamente, en el año 1895 se crea, también en Valparaíso, la Football Association of Chile, la primera asociación de fútbol del país. En los siguientes años se incorporan otros deportes como el boxeo, el ciclismo y el atletismo y, junto con ello, otras ciudades, como es el caso de la capital del país (Santiago), comienzan a ver sus primeros clubes (Modiano, 1997). Por parte del Estado, la primera iniciativa en relación con la actividad física y el deporte se materializa en 1906 con la creación del Instituto de Educación Física de la Universidad de Chile (Guarda, 2006). Respecto a la sociedad civil en general, el Estado reconoce el derecho de libre asociación y de reunión, ello siempre dentro de una tensión entre la clase liberal-conservadora y el Estado (Irarrázaval, Salamon, Hairel y Sokolowski, 2006).

A esta etapa, debemos agregar que la masificación de deportes como el boxeo y el fútbol motivó una actividad económica en torno al deporte, constituyéndose un incipiente mercado del espectáculo deportivo, que no sólo incluyó los tickets de las grandes jornadas deportivas, sino también el surgimiento de una prensa especializada que colaboró en la difusión de esta actividad (Ovalle, 2017).

En cuanto a los clubes, en este ciclo se fundó el 3,5\% de ellos, siendo organizaciones precursoras del asociacionismo chileno, antiguas, de tradición, con orígenes en las clases altas y que han sido testigos privilegiados de las diez últimas décadas del país. Se forjaron, por influencia extranjera, y tuvieron prácticas deportivas limitadas, restringidas al fútbol y a otros deportes de origen inglés.

En síntesis, esta etapa se caracteriza por la llegada del deporte moderno y por la creación de las primeras organizaciones que comienzan a practicar y a promover las disciplinas introducidas por los británicos. El deporte se concentra en las clases altas, reflejando también el período político del país conocido como "oligárquico liberal", ya que estaba encabezado por burgueses.

\section{$2^{a}$ etapa: 1925 - 1938. Surgimiento de otras organizaciones y diversificación}

En Chile, a partir de 1925, se desarrolla una etapa de transformaciones políticas y sociales influenciada por los efectos de la Primera Guerra Mundial, la madurez cívica de la clase media y la mayor concienciación del sector obrero (Eyzaguirre, 1981). A ello se suma una 
Matus, C.; Vilanova, A.; Puig, N., \& Vidal, J. (2018). Las etapas del asociacionismo deportivo en Chile y su relación con el contexto histórico (finales siglo XIX-2012). RICYDE. Revista internacional de ciencias del deporte. 53(14), 280-296. https://doi.org/10.5232/ricyde2018.05308

crisis en el mercado del salitre que deteriora la situación financiera del país. Políticamente, se conoce a este período como República Federal, la cual destaca por sus frecuentes alternancias de poder a nivel político, caracterizadas por los gobiernos temporales e impuestos, en algunas ocasiones, a la fuerza, como es el caso del golpe de Estado del año 1925 liderado por el General Carlos Ibáñez del Campo, que comportó el exilio y la persecución de dirigentes sociales vinculados, principalmente, a la política (Gazmuri, 2012). Sería de suponer que fue un período difícil para el desarrollo de la sociedad civil en general, pero en la práctica ello no se vio reflejado en las organizaciones, ya que se diversificó el nacimiento de éstas, tanto en el ámbito religioso, como en el sindical, entre las mujeres y en organizaciones universitarias, entre otras (CIVICUS - Fundación Soles, 2006; CIVICUS - Fundación Soles, 2010). En síntesis, este período es de alta inestabilidad política. Sin embargo, ello no impide que sea un período de alto crecimiento del asociacionismo civil en Chile, sobre todo en los centros urbanos, donde destacan las organizaciones de trabajadores y de las clases medias (Salazar, 2009; Grez, 2011).

En cuanto al deporte, este pasa de una etapa (inicios del siglo XX) en la que se constituye una práctica propia de la alta sociedad (aristocrática) y con un enfoque recreativo, a una fase más competitiva. A la vez, surgen otros deportes, con sus clubes y asociaciones, como es el caso del baloncesto y del boxeo. También aparecen las primeras federaciones, que, junto con las asociaciones $^{3}$, comienzan a actuar como entes aglutinadores y representativos de los clubes. El deporte comienza a ser practicado por la clase media (es el caso del tenis) y también surgen los primeros medios de comunicación exclusivamente deportivos y de tipo masivo, como la revista Los Sports (1923-1931), la primera en Sudamérica dedicada solo al deporte (Modiano, 1997).

No obstante, es el período de más baja frecuencia de fundaciones de clubes, con solo el 0,7\% de registros, a pesar de que existían las condiciones para entrar en una etapa de asentamiento del sistema. Lo anterior se debe, quizás, a que los esfuerzos del mundo dirigencial no priorizaban a los clubes, sino que se centraron en afianzar a las nuevas organizaciones que surgían, como las asociaciones deportivas y las federaciones deportivas (integradas por clubes y/o asociaciones, al menos tres).

A modo de síntesis, se puede señalar que es una etapa donde el asociacionismo deportivo ve aparecer otras figuras diferentes al club, como son las asociaciones y las federaciones, siempre en un clima político y social inestable. Junto a ello, el deporte emprende un proceso de expansión social a otros niveles, acompañado del establecimiento de otras disciplinas.

\section{$3^{a}$ etapa: 1939 - 1973. Crecimiento del número de clubes}

Los cuarenta años anteriores al golpe de Estado de 1973 en Chile, se caracterizaron por una serie de transformaciones sociales, políticas y económicas, las cuales permitían la inclusión de diversos sectores sociales en un marco institucional y político compartido. No obstante, el inicio de la dictadura militar del año 1973 terminó con esa pauta de desarrollo. En cuanto a la sociedad civil, el año 1968 se posiciona como clave para el asociacionismo en general, ya que se dicta la Ley de Juntas de Vecinos y Organizaciones Comunitarias (actualmente vigente), que legaliza y amplía un conjunto de organizaciones de base territorial, como las juntas de vecinos y los clubes deportivos (CIVICUS - Fundación Soles, 2006), dando inicio a una formalización de la sociedad civil (CIVICUS - Fundación Soles, 2010). En relación con ello,

\footnotetext{
3 Organizaciones deportivas conformadas por al menos tres clubes y cuyo fin era y es, agruparlos y representarlos en instancias superiores.
} 
Matus, C.; Vilanova, A.; Puig, N., \& Vidal, J. (2018). Las etapas del asociacionismo deportivo en Chile y su relación con el contexto histórico (finales siglo XIX-2012). RICYDE. Revista internacional de ciencias del deporte. 53(14), 280-296. https://doi.org/10.5232/ricyde2018.05308

Irarrázaval y col. (2006) afirman que es en esta etapa cuando se inicia la consolidación de las organizaciones que hoy canalizan la mayor parte del voluntariado del país. Esto podría tener relación con que la mayoría de los gobiernos que lideraron el Estado en esta etapa fueron de una línea más social, principalmente de ideologías demócratas, radicales social-demócratas, socialistas y populares (Gazmuri, 2012). Delamaza (2005), señala características que lo corroborarían, ya que existía un sistema político de alta inclusión y ampliación de la participación electoral, y las relaciones laborales se habían institucionalizado, entre otras. Así, la sociedad civil se fue integrando al sistema político, canalizando sus demandas hacia el Estado. Por su parte, Irarrázaval y col. (2006) señalan que la democratización del sistema electoral y la incorporación definitiva de las clases medias a las organizaciones sociopolíticas, consolidaron el proceso de democratización de las organizaciones del sector sin fines de lucro.

En cuanto al deporte, se observa una intención clara por parte del Estado, de participar del sistema deportivo nacional, abordado con distintos matices, de acuerdo con el gobierno de turno. Se generaron una serie de instituciones públicas que buscaban, mediante sus funciones, regular, controlar y apoyar el deporte en general. Entre ellas, se pueden mencionar el Departamento de Deportes de la Dirección de Informaciones y Cultura del Ministerio del Interior, creado en el año 1943; la refundación del Departamento de Deportes el año 1948, dependiente del Ministerio de Defensa; la constitución, en la Cámara de Diputados, de la Comisión de Educación Física y Deportes en 1954. Por otro lado, si bien no eran instituciones públicas, también existían el Comité Olímpico de Chile (1934) y la Comisión Nacional de Deportes (1940). Así mismo, se realizó un catastro de clubes no afiliados a federaciones (1957), se promulgó la Ley sobre Deportes y Recreación (1970), se creó la Dirección General de Deportes y Recreación (DIGEDER) y se formuló la Política Nacional de Desarrollo del Deporte y la Recreación (1972-1976) (Muñoz, 2001). Junto a lo anterior, el gobierno de la época estableció regulaciones laborales a las organizaciones que contaran con deportistas profesionales, reconociéndoles a éstos su condición de trabajadores, y otorgándoles beneficios que hasta ese momento no contaban (Vidal, 2014).

Durante el gobierno de la Unidad Popular (1970-1973), Chile y Cuba suscriben un acuerdo de mutua cooperación deportiva. Mientras Chile asesora a los caribeños en fútbol, tenis, equitación y hockey césped, los cubanos asesoran en las disciplinas del voleibol, las pesas y el béisbol. Este acuerdo será interrumpido a partir del Golpe de Estado del año 1973 (Marín, 2010).

Para los clubes, esta etapa se posiciona como la segunda más fructífera $(14,8 \%)$, lo cual puede verse influenciado por el hecho de que abarca treinta y cuatro años. Pero, a pesar de lo anterior, fue una fase que contó con muchas condiciones que acogían positivamente el surgimiento del asociacionismo. Los clubes que nacen entonces, lo hacen en tiempos mayoritariamente democráticos, donde el Estado demostraba interés por potenciar a la sociedad civil. Se aprecia una participación más directa del Estado en el asociacionismo deportivo, manifestada tanto por el apoyo de sus actividades como por velar por el correcto ejercicio de sus acciones. El Estado buscaba ordenar el funcionamiento de sus organizaciones deportivas y también apoyarlas, principalmente a través de la tecnificación del recurso humano con la participación de técnicos extranjeros. Este período fue relevante para el asociacionismo, ya que existían las condiciones para crecer cuantitativa y cualitativamente. 
Matus, C.; Vilanova, A.; Puig, N., \& Vidal, J. (2018). Las etapas del asociacionismo deportivo en Chile y su relación con el contexto histórico (finales siglo XIX-2012). RICYDE. Revista internacional de ciencias del deporte. 53(14), 280-296. https://doi.org/10.5232/ricyde2018.05308

\section{$4^{a}$ etapa: 1974 - 1990. Limitaciones y control}

Este período coincide con la dictadura del general Pinochet, etapa en la cual el trabajo que venían desarrollando tanto las organizaciones de la sociedad civil como el Estado se vio claramente afectado. La ampliación de las organizaciones sociales se vio frustrada, el modelo de desarrollo económico se alteró radicalmente y, con ello, también las pautas sociales y culturales. El vínculo entre el Estado y la sociedad civil se modificó, al igual que la figura de esta última, en el contexto del neoliberalismo (Vidal, 2008). De acuerdo con esto, existe un cambio radical de sistemas, ya que, de una economía interna y con alta participación del Estado, se pasa a una economía abierta, orientada a la exportación de recursos y a la privatización de servicios.

Respecto al asociacionismo en esta etapa, Irarrázaval y col. (2006, p. 47) señalan que:

"Durante los primeros años del gobierno militar, diversas organizaciones de la sociedad civil fueron intervenidas y vigiladas. Si bien la mayoría de las entidades comunitarias lograron persistir, perdieron su autonomía, sus dirigentes fueron designados y sus atribuciones y potencialidades de acción fueron reducidas. Algo muy similar sucedió con las asociaciones gremiales y sindicatos. Por lo tanto, la década de los setenta presenta una fuerte disminución de la cantidad de organizaciones del sector sin fines de lucro, como consecuencia de las características propias que implica un quiebre democrático"

Lo anterior se comprende bajo la lógica de funcionamiento de las dictaduras, que buscan, mediante el amedrentamiento y la coerción, evitar acciones que pongan en riesgo el poder logrado mediante la implantación de su modelo de gobierno. No obstante esto, la dictadura generó estrategias para el desarrollo del deporte amateur, por medio de los municipios, que se transformaron en un vehículo de la política social y cultural del gobierno de Pinochet. Se debe recordar que la dictadura poseía un proyecto refundacional de la sociedad chilena (Hunneus, 2001) y que encabezó una estrategia de transformación del modelo de desarrollo socioeconómico, que estaba orientado según las ideas neoliberales de reducción del gasto fiscal, privatización de los servicios sociales y la no intervención económica del Estado en el funcionamiento de la economía. De acuerdo con este esquema, una parte importante de los servicios sociales, de la educación y de la salud, por ejemplo, fueron traspasados a las municipalidades. El deporte no fue una excepción y, desde ese momento, los clubes deportivos debieron establecer relaciones con estos organismos comunales, ya que la DIGEDER traspasaba dinero a los clubes por medio del municipio que era el interlocutor con el que debían relacionarse las organizaciones deportivas. En este sentido, Donoso (2011), manifiesta que la política deportiva fue parte de la municipalización de la política social. Por medio de este mecanismo el estado autoritario pudo cumplir dos objetivos: 1) reducir el gasto social por medio del traspaso de la administración de los servicios sociales, y 2) someter a control político a las organizaciones de la sociedad civil, entre ellas las deportivas, ya que la vía de financiación por medio de fondos concursables requería de la aprobación de las autoridades políticas locales, que debían conocer las orientaciones políticas de estas organizaciones, impidiéndoles la financiación a quienes asumieran posiciones críticas hacia el gobierno.

El miedo fue un dispositivo de control social que usó la dictadura, el cual afectó la vida cotidiana de las personas, pero también de las organizaciones sociales, ya que su accionar podía finalizar en la represión física de los dirigentes y asociados, o por medio de obstáculos burocráticos que impidieran su funcionamiento (Lechner, 1981). El miedo provoca lo que Barraza (1980) ha denominado "ensimismamiento de lo cotidiano", fenómeno según el cual 
Matus, C.; Vilanova, A.; Puig, N., \& Vidal, J. (2018). Las etapas del asociacionismo deportivo en Chile y su relación con el contexto histórico (finales siglo XIX-2012). RICYDE. Revista internacional de ciencias del deporte. 53(14), 280-296. https://doi.org/10.5232/ricyde2018.05308

los mecanismos de control social del autoritarismo intervienen en la vida cotidiana, llegando a controlar las subjetividades donde se desarrollan estrategias de supervivencia, por sobre aquellas de articulación de acciones colectivas, lo que afecta la constitución de actores colectivos.

En el caso del asociacionismo deportivo, estas acciones y éste contexto se pueden ver reflejados también en el caso español, donde la dictadura franquista generó acciones de censura, tal como se puede apreciar en el estudio de los clubes deportivos catalanes (Secretaria General de 1'Esport, 2010). En línea con lo anterior, pero para el caso chileno, durante los diecisiete años del régimen militar, el potenciamiento del asociacionismo no estuvo entre las prioridades del gobierno (representado por la figura de la Dirección General de Deportes y Recreación - DIGEDER). De hecho, muchas funciones ejecutadas históricamente por las organizaciones deportivas son traspasadas al sector público, entre ellas, la organización de competiciones y la capacitación de recursos humanos (Feller, Alvarado, Bossay, y García, 2013).

Cabe mencionar que no existen menciones significativas de las organizaciones deportivas en la documentación oficial existente, salvo la realización del Censo de Organizaciones Deportivas de los años 1984 y 1985. Es relevante señalar que en este período el deporte continuó bajo el alero del Ministerio de Defensa, se recalcó el carácter subsidiario de la acción del Estado, se puso énfasis en la práctica deportiva a fin de desarrollar la salud físicamental, fortalecer la raza y aumentar la capacidad física, entre otras acciones (Muñoz, 2001).

Recapitulando, el asociacionismo en general sufrió un fuerte estancamiento debido a las condiciones impuestas por la dictadura militar, que coartó las libertades individuales y las colectivas, limitando e interviniendo el espacio público de participación de la sociedad civil.

El poco significativo $2.8 \%$ de clubes que se fundaron en este período no deja de ser el reflejo patente de las condiciones precarias y limitantes en que se forjó y se desarrolló el asociacionismo deportivo. Los clubes que surgen en esta etapa pueden haberse moldeado por intereses políticos y con mucho control por parte de los miembros de la junta directiva.

\section{$5^{a}$ etapa: 1991 - 2000. Reconstrucción de la sociedad civil}

El fin de la dictadura militar chilena (1973 - 1990), y con ello el retorno de la democracia, implicó el desarrollo de importantes cambios en el asociacionismo en general. La sociedad civil presentó una gran expansión de iniciativas en cuanto a voluntariado, a desarrollo ambiental, en el ámbito indígena y en las regiones (CIVICUS - Fundación Soles, 2010). Esto por iniciativa de los gobiernos democráticos posteriores a la dictadura que comenzaron a tomar medidas para fortalecer la sociedad civil en el proceso de consolidación de la democracia, priorizando el área social, aumentando el gasto social, fortificando la institucionalidad y ampliando la oferta programática (Irarrázaval y col., 2006).

Las organizaciones del deporte y de la sociedad civil en general, comienzan a recibir por parte del Estado el trato que se les había negado durante la dictadura. No obstante, a pesar de estas transformaciones, el deporte continúa siendo gestionado por el Ministerio de Defensa. Esta fase (1991 - 2000) reciente de Chile, que contó con dos Presidentes de la República de la misma tendencia política de centro-izquierda, generó las siguientes acciones: se reestablece a plenitud la libertad de asociación, el acceso al deporte se ve como un derecho fundamental de las personas, se crea un Consejo Asesor Presidencial para el Deporte y la Recreación (1994), se crea la Política Nacional de Deportes (1996), se envía el proyecto de la Ley del Deporte, se promueve la constitución y el desarrollo de clubes y demás organizaciones 
Matus, C.; Vilanova, A.; Puig, N., \& Vidal, J. (2018). Las etapas del asociacionismo deportivo en Chile y su relación con el contexto histórico (finales siglo XIX-2012). RICYDE. Revista internacional de ciencias del deporte. 53(14), 280-296. https://doi.org/10.5232/ricyde2018.05308

deportivas y se sugiere mantener un registro nacional de organizaciones y ejercer supervisión sobre estas (Muñoz, 2001).

En esta etapa post dictadura, el asociacionismo deportivo se encuentra en un proceso de ajustes y de transición, al igual que toda la sociedad chilena, amparado en la función más social, participativa y prioritaria que va adquiriendo el deporte para los gobiernos democráticos.

El 10,6\% de clubes que se fundan en esta etapa, contrasta con el 2,8\% que emergió durante el régimen militar. Estas organizaciones nacen en un clima de transición, de restablecimiento de condiciones para el asociacionismo y que implica un nuevo trato de confianza entre las autoridades democráticas y el ámbito dirigencial.

\section{6 ${ }^{a}$ etapa: 2001 - 2012. La consolidación}

En este período se realizan cambios estructurales en el deporte desde el aparato público. Entre ellos se promulga una nueva Ley del Deporte $n^{\circ} 19712$ (Ministerio del Interior de Chile, 2001) que viene a reemplazar la del año 1970 y se acompaña de una nueva Política Nacional de Actividad Física y Deportes (Instituto Nacional de Deportes, 2002a), que durante los últimos años ha fijado los lineamientos y prioridades estatales en la materia. Respecto a la influencia y a la relación de estas nuevas herramientas (Ley del Deporte y Política Nacional) con las organizaciones deportivas, la revisión ha permitido detectar claras alusiones a ellas. Entre las más destacadas se pueden mencionar:

- Se reconoce el concepto y la función de las organizaciones deportivas.

- Se caracterizan e identifican a todas las organizaciones deportivas de tipo voluntario.

- Se crean el Registro Nacional de Organizaciones Deportivas (RNO) y el Reglamento de Organizaciones Deportivas.

- Queda establecido que el Estado debe velar por la autonomía y la libertad de asociación de las organizaciones deportivas.

- Se crea un Departamento de Organizaciones Deportivas a nivel nacional y también en cada región del país.

Estas acciones posicionan a las entidades deportivas como protagonistas en el desarrollo de uno de los principios de la Política Nacional: el de Participación de la Comunidad.

Que el 67,6\% de los clubes encuestados se haya fundado durante estos años (2001 - 2012), indica que son organizaciones de creación reciente en una primera aproximación, gestadas en una fase democrática y de pleno derecho del asociacionismo en ese país. En esta etapa el Estado reordena y norma el asociacionismo deportivo, fomentando considerablemente el surgimiento de organizaciones, apoyado en el establecimiento de vías de financiamiento y en el reconocimiento legal y político. No obstante, el Estado también requirió que estas organizaciones reconocidas por la Ley del Deporte (Ministerio del Interior, 2001), cumplieran con una serie de requisitos y además desarrollaran acciones establecidas en el Reglamento de Organizaciones Deportivas (Instituto Nacional de Deportes, 2002b), las cuales tenían por objetivo normalizar procedimientos y también resguardar los recursos públicos invertidos. 
Matus, C.; Vilanova, A.; Puig, N., \& Vidal, J. (2018). Las etapas del asociacionismo deportivo en Chile y su relación con el contexto histórico (finales siglo XIX-2012). RICYDE. Revista internacional de ciencias del deporte. 53(14), 280-296. https://doi.org/10.5232/ricyde2018.05308

En síntesis, los clubes se encuentran en una etapa de consolidación, amparados en las condiciones que entrega el Estado, producto también del proceso de maduración de la sociedad civil chilena post dictadura. Se suman a lo anterior, las estrategias diseñadas por los gobiernos para apoyar el desarrollo de las organizaciones, donde se encuentran principalmente: la capacitación del recurso humano (técnico y dirigencial) y el fomento de apoyos económicos, como FONDEPORTE ${ }^{4}$ y el Fondo $2 \%$ del FNDR ${ }^{5}$ para Deportes. Complementan esto, las acciones emanadas desde las municipalidades en cuanto al apoyo monetario y en infraestructura.

\section{Discusión: Contrastando los resultados con otras investigaciones}

Este trabajo tuvo como objetivo describir las etapas del asociacionismo deportivo de Chile en el contexto del desarrollo histórico de este país. Se han logrado como resultados una serie de etapas que se caracterizan por responder a rasgos identificatorios que se han podido verificar en otros estudios. Hablamos particularmente de la influencia inglesa en algunos países, no tan solo como fenómeno migratorio y social, sino que también en la instalación de ciertas disciplinas deportivas, las cuales se desarrollaban principalmente en la burguesía. En el caso de Chile, las circunstancias que otorgan las bases de la instalación de ciertos deportes y sus organizaciones, se asemeja bastante a cómo se gestó el desarrollo del asociacionismo en España (Torrebadella, 2012; Puig y col., 1996; Puig y col., 1999b; Simón, 2015) y también en Argentina (Frydenberg y col., 2013). Países que al igual que Chile se caracterizaron por poseer puertos con alto tráfico comercial durante los siglos XIX y XX, a través de los cuales el deporte "moderno" ingresó como práctica informal para luego consolidarse institucionalmente en la figura de los clubes deportivos.

Una diferencia que se detecta entre el caso chileno y español, es que posiblemente debido a la distancia y costos entre Chile e Inglaterra y Europa en general, la influencia de inmigrantes europeos en la génesis del deporte moderno y del tejido asociativo del país sudamericano, sea más significativa que la generada producto de los viajes de estudiantes chilenos o profesionales a Europa en aquellos años, como si sucedió en España.

En cuanto al contexto en el cual se desarrollaron las etapas señaladas en los resultados, las situaciones históricas (económicas, políticas y sociales) han influenciado al asociacionismo deportivo. Nos referimos puntualmente al marco que limitó y orientó a esas organizaciones cuando han existido dictaduras o regímenes totalitarios gobernando los países, como ha sido el caso de Argentina (Frydenberg y col., 2013), España (Puig y col., 1999a) y Alemania (Kruger, 2013). Las situaciones vividas en dichos países fueron similares a las acontecidas en Chile, aunque, si bien existieron diferencias temporales y de otros matices, se apreció un denominador común, el cual es la intervención y control que ejerció el Estado hacia estas organizaciones deportivas, tanto voluntarias o de base como profesionales, ejecutando acciones tales como la refundación de estas instituciones bajo normativas puntuales de esos "estados" y/o limitando el surgimiento de estas mismas. En el caso de Chile, esto cobra

\footnotetext{
${ }^{4}$ El Fondo Nacional de Nacional para el Fomento del Deporte es una herramienta de financiamiento para el desarrollo de la actividad física y deportiva del país, a cargo del Instituto Nacional de Deportes (IND). Este fondo tiene como objetivo financiar total o parcialmente proyectos. A él, postulan organizaciones privadas (clubes, asociaciones, federaciones, etc.) y públicas. Esta fuente de financiamiento nace el año 2002.

${ }^{5}$ Es una fuente de financiamiento de tipo concursable para proyectos deportivos y se encuentra administrada por los Gobiernos Regionales chilenos. A este fondo postulan clubes, asociaciones, federaciones, municipalidades, etc., con el objetivo de obtener recursos económicos. Es un concurso que se inicia el año 2009.
} 
Matus, C.; Vilanova, A.; Puig, N., \& Vidal, J. (2018). Las etapas del asociacionismo deportivo en Chile y su relación con el contexto histórico (finales siglo XIX-2012). RICYDE. Revista internacional de ciencias del deporte. 53(14), 280-296. https://doi.org/10.5232/ricyde2018.05308

mucho sentido, ya que las dos etapas con menos clubes fundados, correspondieron a fases en las cuales se desarrollaron dictaduras y gobiernos inestables.

Siguiendo en este avance del asociacionismo, se aprecia como en las fases posteriores a la dictadura chilena de Pinochet (finalizada en 1990), el surgimiento de clubes es significativo en relación a las otras etapas. Este fenómeno respondería a las nuevas consideraciones y normativas que buscaban potenciar este sector postergado de la sociedad. Se detecta un hecho similar en los clubes catalanes en España, los cuales aumentan considerablemente a partir del final de la dictadura franquista que afectó a ese país (Secretaria General de l'Esport, 2010). En el caso alemán, se generan dos tipos de situaciones post Segunda Guerra Mundial (Kruger, 2013). En primer lugar se disuelven la totalidad de clubes, para luego presentarse dos escenarios, uno que respondía al renacimiento de estas organizaciones y que correspondía a la Alemania Occidental, y por otro, un modelo de control por parte del Estado, el cual se basaba en "grupos deportivos", vinculados a ciertas organizaciones de la sociedad, y que se gestaba en la República Democrática Alemana.

\section{Conclusiones}

Es posible afirmar que el contexto en el que se ha gestado el asociacionismo deportivo chileno, se relaciona con la dinámica social de cada época (Moreno, 1993), lo cual coincide con las características de la sociedad imperante en aquellos momentos, siendo éstas, limitantes y/o potenciadoras para el desarrollo y crecimiento del asociacionismo deportivo.

El proceso de instalación y de desarrollo de los clubes chilenos, ha sido influido por las características propias de los sistemas sociales desde donde han surgido. En efecto, hechos como la influencia inglesa (Lagardera y Puig, 1996; Pujadas y Santacana, 2003; Torrebadella y Nomdedeu, 2013; Puig y col., 1999a; Frydenberg y col., 2013; Simón, 2015) en Chile, permiten dar respuesta en gran medida a los orígenes del asociacionismo deportivo en ese país, y a cómo se vio influenciado, no solo en su comienzo, sino también en la cultura que otorga identidad a estas organizaciones (Oviedo y Zarpellon, 2012).

En cuanto al desarrollo que tuvo el asociacionismo durante el siglo XX, los fenómenos socio políticos, siendo el caso puntual de gobiernos inestables y dictaduras que vivió ese país, generaron efectos negativos en su asociacionismo, en este sentido, situaciones similares se han evidenciado en otros contextos (Kruger, 2013; Frydenberg y col., 2013; Secretaria General de l'Esport, 2010). Es relevante destacar que posterior a estas etapas que afectaron el desarrollo del asociacionismo, no solo chileno, sino que también de los otros casos, han surgido otros períodos que vienen a mejorar las condiciones para el nacimiento y/o resurgimiento de las organizaciones deportivas.

En función de los resultados, es necesario considerar que el registro de clubes empleado en este estudio, no contiene a todas las organizaciones del país. Si así se hiciera y se incluyeran las que se mantienen al margen del RNO, se podrían alterar en alguna medida los resultados expuestos. No obstante, lo pesquisado y mostrado, es coherente en función de la literatura y de las realidades de las organizaciones deportivas actuales.

Este estudio y su relación con otros trabajos pertenecientes a contextos similares, abre el desafío e interés por afrontar investigaciones en otras dimensiones del asociacionismo deportivo. De acuerdo a ello, emanan retos para la investigación de este sector, ya sea empleando enfoques cualitativos o cuantitativos, y ubicándose no solo en los procesos históricos y sociales, sino también abordando otras variables, como la economía, el género, la oferta, el voluntariado, etc. Esto cobra aún más sentido, considerando la relevancia que 
Matus, C.; Vilanova, A.; Puig, N., \& Vidal, J. (2018). Las etapas del asociacionismo deportivo en Chile y su relación con el contexto histórico (finales siglo XIX-2012). RICYDE. Revista internacional de ciencias del deporte. 53(14), 280-296. https://doi.org/10.5232/ricyde2018.05308

adquiere la diversidad que existe actualmente en los clubes deportivos (Kay, 2013; Koski, 2012; Matus, 2015; Secretaria General de l'Esport, 2010).

\section{Agradecimientos}

Los autores agradecen al Instituto Nacional de Deportes de Chile, quién a través del Fondo Nacional para el Fomento del Deporte del año 2013, en el área de Ciencias del Deporte, han colaborado en la financiación del proyecto "Prácticas físico-deportivas ofertadas por los clubes deportivos de base en las regiones de Maule y Biobío. Análisis desde su estructura organizacional", código № 1300120015, desde el cual ha surgido este artículo. También se agradece al Institut Nacional d'Educació Física de Catalunya y al Grup d'Investigació Social i Educativa de l'Activitat Física i I'Esport (GISEAFE) del mismo por otorgar el apoyo técnico para el desarrollo de esta investigación.

\section{Referencias}

Barraza, X. (1980). Notas sobre la vida cotidiana en un orden autoritario. Revista Araucaria, 11.

CIVICUS; Fundación Soles. (2006). Índice de la sociedad civil de Chile. Chile: la reconstrucción asociativa de un país. Santiago. Tomado el 05 de enero de 2017. Disponible en: https://goo.gl/GES8WY

CIVICUS; Fundación Soles. (2010). Informe analítico nacional: Índice de la Sociedad Civil. Chile 2009 - 2010. Tomado el 28 de marzo de 2017. Disponible en: http://www.avina.net/avina/wpcontent/uploads/2013/06/Informe_Analitico_ISC_Chile_2010.pdf

Cornejo, M., Salcedo, P., y Matus, C. (2010). Análisis organizacional y administrativo de los clubes deportivos escolares de la Provincia de Concepción. Informe Final FONDEPORTE - IND. Concepción - Chile.

Delamaza, G. (2005). Tan lejos tan cerca: políticas públicas y sociedad civil en Chile. Chile. LOM Ediciones.

Donoso, K. (2012). "Deporte y recreación para todos..." Política social y cultural de la DIGEDER en los municipios de Santiago. En V. Valdivia, R. Álvarez y K. Donoso (Eds), La Alcaldización de la política. Los municipios en la dictadura pinochetista. Santiago: LOM Ediciones.

Elsey, B. (2012). Citizens and Sportsmen: Fútbol and Politics in Twentieth-Century Chile. Estados Unidos: University of Texas Press.

Eyzaguirre, J. (1981). Historia de las instituciones políticas y sociales de Chile. Chile. Editorial Universitaria.

Feller, C., Alvarado, P., Bossay, C., y García, I. (2013). Gestión deportiva municipal en Chile: una mirada desde la investigación social. En D. Martínez (Ed.), La Gestión Deportiva Municipal en Iberoamérica: Historia, Teoría y Práctica ( $1^{\text {a }}$ ed.). Madrid: Librerías Deportivas Esteban Sanz, S.L.

Fernandes da Silva, C., y Zarpellon, J. (2015). Uma história das instrumentalidades do esporte no campo do associativismo esportivo em Porto Alegre/RS. Revista Movimento, 2(21), 377-389.

Frydenberg, J., Daskal, R., \& Torres, C. (2013). Sports Clubs with Football in Argentina: Conflicts, Debates and Continuities. The International Journal of the History of Sport, 14(30), 1670-1686.

https://doi.org/10.1080/09523367.2013.831840 
Matus, C.; Vilanova, A.; Puig, N., \& Vidal, J. (2018). Las etapas del asociacionismo deportivo en Chile y su relación con el contexto histórico (finales siglo XIX-2012). RICYDE. Revista internacional de ciencias del deporte. 53(14), 280-296. https://doi.org/10.5232/ricyde2018.05308

Gazmuri, C. (2012). Historia de Chile 1891 - 1994. Política, economia, sociedad, cultura, vida privada, episodios. ( $1^{\mathrm{a}}$ ed.). Santiago, Chile: RiL editores.

Grez, S. (2011). Historia del comunismo en Chile. La era de Recabarren (1912-1924). Santiago: LOM Ediciones.

Guarda, S. (2006). Historia del Instituto de Educación Física. Revista de Educación Física - Chile, 256, 13-36.

Guerrero, B. (2005). A favor del viento. Maestranza Foot-Ball Club. Historia de un Club Deportivo. 1905-2005. Chile: Ediciones El Jote Errante y Ediciones Campvs.

Guerrero, B. (2009). Yungay. Marca registrada del fútbol iquiqueño. Chile: Ediciones El Jote Errante

Heinemann, K., \& Schubert, M. (1994). Der Sportverein: Ergebnisse einer repräsentative Untersuchung (Vol. 1). Stuttgart: Schorndorf: Hofmann.

Huneeus, C. (2000). El régimen de Pinochet. Santiago: Editorial Planeta.

Instituto Nacional de Deportes de Chile. (2002a). Política Nacional de Actividad Física y Deportes. Tomado el 15 de julio de 2016. Disponible en http://www.mindep.cl/wpcontent/uploads/2014/11/Politica-Nacional-IND.pdf

Instituto Nacional de Deportes. (2002b). Reglamento de Organizaciones Deportivas. Santiago, Chile.

Instituto Nacional de Estadísticas de Chile. (2016). Página web oficial del Instituto Nacional de Estadísticas de Chile. Demográficas y vitales. Productos estadísticos. Tomado el 20 de diciembre de 2016. Disponible en http://www.ine.cl/canales/chile_estadistico/familias/demograficas_vitales.php

Irarrázaval, I; Salamon, L; Hairel, E., y Sokolowski, S. W. (2006). Estudio Comparativo del Sector Sin Fines de Lucro. Chile. Santiago.

Kay, J. (2013). 'Maintaining the Traditions of British Sport'? The Private Sports Club in the Twentieth Century. The International Journal of the History of Sport, 14(30), 16551669.

https://doi.org/10.1080/09523367.2013.831839

Koski, P. (2012). Finnish sports club as a mirror of society. International Journal of Sport Policy and Politics, 2(4), 257-275.

https://doi.org/10.1080/19406940.2012.656852

Krüger, M. (2013). The History of German Sports Clubs: Between Integration and Emigration. The International Journal of the History of Sport, 14(30), 1586-1603. https://doi.org/10.1080/09523367.2013.822862

Lagardera, F., y Puig, N. (1996). Procesos de racionalización, diversificación y retroprogresión en los orígenes y evolución actual del deporte en Cataluña. Reflexiones preliminares. En La actividad física y el deporte en un contexto democrático (1976-1996) (pp. 109-208). Pamplona: AEISAD.

Lechner, N. (1981). Acerca del ordenamiento de la vida social por medio del Estado. Revista Mexicana de Sociología, 3(43).

Marín, E. (2010). Historia del deporte chileno. Entre la ilusión y la pasión. Cuadernos del Bicentenario. Santiago de Chile. 
Matus, C.; Vilanova, A.; Puig, N., \& Vidal, J. (2018). Las etapas del asociacionismo deportivo en Chile y su relación con el contexto histórico (finales siglo XIX-2012). RICYDE. Revista internacional de ciencias del deporte. 53(14), 280-296. https://doi.org/10.5232/ricyde2018.05308

Matus, C. La situación de los clubes deportivos chilenos. El caso de la región del Biobío. Tesis doctoral. Barcelona: Universidad de Barcelona - INEFC Barcelona.

Ministerio del Interior de Chile. (1997). Ley $n^{\circ}$ 19418, sobre Juntas de Vecinos y demás Organizaciones Comunitarias. Chile.

Ministerio del Interior de Chile. (2001). Ley del Deporte $n^{\circ}$ 19712. Chile.

Miranda, D., Araneda, G., Jofré, N., y González, R. (2014). Relatos, himnos y camisetas. Clubes deportivos y vida barrial en Quinta Normal. Chile: Editorial Victorino Lainez.

Modiano, P. (1997). Historia del deporte chileno. Orígenes y transformaciones. 1850 1950 ( $1^{a}$ ed.). Chile: Mallea Impresores, LTDA.

Moreno, A. (1993). El asociacionismo deportivo en España. Revista Apunts. Educación Física y Deportes, 33, 58-63.

Muñoz, C. (2001). Historia de la Dirección General de Deportes y Recreación. Las políticas estatales de fomento al deporte. DIGEDER 1948 - 2001. Chile: Departamento de Comunicación Social del Instituto Nacional de Deportes de Chile.

Ovalle, A., y Vidal, J. (2015). Pelota de trapo. Fútbol y deporte en la historia popular. Santiago: Editorial Quimantú.

Ovalle, A. (2017). Entre ideal formativo y fenómeno de masas. La difusión y consolidación del boxeo en Santiago de Chile (1900-1940). Tesis para optar al grado de Doctor en Historia, Mención Historia de Chile. Santiago: Universidad de Chile.

Oviedo, T., y Zarpellon, J. (2012). O abrasileiramento do clube de remo dos italianos em Porto Alegre nas décadas de 1930-1940. Revista Movimento, 3(18), 51-71

Puig, N., García, O., y López, C. (1999a). Clubs deportivos en España. En Participación deportiva: perspectiva ambiental y organizacional (pp. 53-81). Madrid: Consejo Superior de Deportes.

Puig, N., García, O., y López, C. (1999b). Sports Clubs in Spain. En K. Heinemann (Ed), Sport Clubs in various European Countries (pp. 71-99). Stuttgart: Schorndorf: Hofmann.

Puig, N., y Heinemann, K. (1991). El deporte en la perspectiva del año 2000. Papers. Revista de Sociología, (38), 123-141.

https://doi.org/10.5565/rev/papers/v38n0.1613

Puig, N., Moreno, A., y López, C. (1996). Propuesta de marco teórico interpretativo sobre el asociacionismo deportivo en España. Revista Motricidad, (2), 75-92.

Pujadas, X., y Santacana, C. (2003). El club deportivo como marco de sociabilidad en España. Una visión histórica (1850-1975). Revista Española de Historia. Hispania, 214(63), 505-522.

https://doi.org/10.3989/hispania.2003.v63.i214.222

Salazar, G. (2009). Del poder constituyente de asalariados e intelectuales (Chile, siglos $X X$ y $X X I$ ). Santiago: LOM Ediciones.

Santa Cruz, E. (2006). Los comienzos de nuestro Olimpo. Los deportistas como nuevas figuras públicas en Chile en las primeras décadas del siglo XX. Revista Comunicación y Medios, 17, 1-8.

Secretaria General de l'Esport. (2010). Els clubs esportius a Catalunya. Barcelona.

Simón, J. (2015). Construyendo una pasión: El fútbol en España, 1900-1936. La Rioja: UNIR Editorial. 
Matus, C.; Vilanova, A.; Puig, N., \& Vidal, J. (2018). Las etapas del asociacionismo deportivo en Chile y su relación con el contexto histórico (finales siglo XIX-2012). RICYDE. Revista internacional de ciencias del deporte. 53(14), 280-296. https://doi.org/10.5232/ricyde2018.05308

Torrebadella, X. (2012). Orígenes del fútbol en Barcelona. RICYDE. Revista Internacional de Ciencias del Deporte, 27(8), 80-102.

https://doi.org/10.5232/ricyde2012.02706

Torrebadella, X., y Nomdedeu, A. (2013). Foot-ball, futbol, balompié... Los inicios de la adaptación del vocabulario deportivo de origen anglosajón. RICYDE. Revista Internacional de Ciencias del Deporte, 31(09), 5-22.

https://doi.org/10.5232/ricyde2013.03101

Vidal, P. (2008). Para una crítica de la sociedad civil en Chile: una mirada a la historia y algunas de las políticas públicas. Revista del Magíster en análisis sistémico aplicado a la sociedad - MAD, 18, 57-96.

Vidal, J. (2014). Historia social del fútbol: una industria cultural de trabajadores y ciudadanos. Revista SudHistoria, 8, 83-109. 